\title{
ORO, PLATA Y MERCURIO, NERVIOS DE LA MONARQUÍA DE ESPAÑA
}

\author{
ÁLVARO ESPINA MONTERO \\ Ministerio de Economía
}

\begin{abstract}
RESUMEN
El carácter distintivo de la monarquía española durante toda la Edad Moderna fue el dominio de las principales zonas del planeta productoras de plata y mercurio, lo que le proporcionó una ventaja monetaria comparativa prácticamente inexpugnable, especialmente durante el periodo de siglo y medio que siguió a la introducción del patrón-plata en la China de los Ming, en que la relación bimetálica plata/oro resultó extremadamente favorable para la plata. Esto permitió que el poder imperial descansase sobre una combinación sencilla de políticas extractivas, logísticas y financieras, cuyo indicador privilegiado es el mercado del azogue, que se reconstruye en este trabajo.
\end{abstract}

\section{ABSTRACT}

The distinctive character of the Spanish monarchy all along the modern age was the domination on the main producing zones of silver and mercury in the planet, which provided practically uncontestable a comparative monetary advantage to her, specially during the period of century and a half following the introduction of the silver-standard in the Ming's China, during which the bimetallic relation was extremely favorable for the silver. This allowed the imperial power to rest on an very simple combination of extractive, logistic and financial policies, whose privileged indicator is the market of the mercury, that reconstructs in this work.

N. de E.: Fecha de recepción del artículo en la Revista de Historia Económica: enero, 2001. Fecha de aprobación por el Consejo de Redacción: noviembre, 2001. 


\section{INTRODUCCIÓN *}

El hecho de que durante la primera mitad del siglo xvi España pasase de ser un país de segundo o tercer orden a ser el país más rico y poderoso del mundo fue atribuido por Cipolla (1999) a la sucesión de «golpes de fortuna» que comienza con la conquista, expolio y destrucción de los imperios Azteca (1521) e Inca (1532) por Cortés y Pizarro y culmina con la introducción de la amalgama en México por Bartolomé de Medina en 1554, utilizando para ello el azogue de las minas de Almadén —usufructuadas directamente por el monarca - y con el descubrimiento en 1563 de la mina de cinabrio de Huencavélica, que permitió introducir la amalgama en la de Potosí, situada a $1.200 \mathrm{~km}$. La apelación al azar para explicar la hegemonía española había sido popularizada, ya en el siglo Xvil, por el abate Raynal y por Adam Smith. Montesquieu (1734, cap. XVII), por su parte, afirmaba que el descubrimiento de las Indias había producido en Europa la misma revolución que la conquista de Egipto por Augusto y el traslado del tesoro de Ptolomeo a Roma.

Sin embargo, existe una explicación alternativa más acorde con los hechos hoy conocidos. En síntesis, estos hechos indican que a finales del siglo $\mathrm{XV}$ el continente europeo se encontraba falto de numerario. Como el final de la Guerra de Cien Años - y de la peste- supuso la recuperación de la demanda agregada europea, tal escasez provocó una caída de precios del orden del 35 por 100 en torno a 1450, revalorizando la plata en igual proporción, lo que impulsó la revolución tecnológica experimentada por la producción de metales monetizables en el sur de Alemania y Europa Central.

A ello se unió el hecho sin precedentes de que en torno a 1445 los comerciantes del sur de la China optaran por la «argentización» para defenderse del colapso del sistema monetario y de la hiperinflación, que en 1426 había multiplicado los precios en dinero de papel por 1.000 en cincuenta años (Maddison, 2001), lo que desencadenó la explosión del comercio marítimo intercontinental de especies metálicas que sirvió de contrapartida al de las especias. La avidez de plata de sus sistemas monetario y fiscal convirtieron al imperio Chino en una verdadera bomba absorbente de este metal durante los dos siglos siguientes (Flynn y Giráldez, 1996). $\mathrm{El}$ ingente aumento de la demanda de plata produjo la aparición de beneficios extraordinarios en el comercio intercontinental de este metal.

* Agradezco los comentarios y sugerencias de Piero Tedde y David Reher a una versión anterior, mucho más amplia, de este trabajo, $y$ los de tres evaluadores anónimos. 
Durante el siglo que siguió al cambio monetario chino, la extracción de plata en Europa Central se multiplicó por cinco, con una producción total de dos mil toneladas (Munro, 1999b). Pese a este descomunal aumento de la producción, el siglo $\mathrm{xV}$ continuó siendo deflacionista hasta el final (los precios cayeron en torno a un 30 por 100 a lo largo del siglo), y sólo en el tercer decenio del siglo XVi, cuando llegó la riada de metal americano, empezó a registrarse una inflación persistente, aunque moderada. Las mejoras en las técnicas de laboreo y fundición habían reducido drásticamente el coste de producción, lo que, ceteris paribus, debería haber reducido también su valor de mercado, elevando los precios de los restantes productos medidos en plata. Pero lo que ocurrió durante la segunda mitad del siglo XV fue todo lo contrario: la plata aumentó de valor, cayendo los precios-plata. A partir de los años veinte del siglo xvi la tendencia de los precios se invirtió, pero con una intensidad inconmensurable respecto a la magnitud de la producción y de los metales transferidos a Europa: en Castilla la Nueva la inflación -medida en precios/plata- no llegó a superar el 2 por 100 anual a medio y largo plazo: iasí de modesta fue la «revolución de los precios»! Además, la inflación fue mayor antes de la introducción de la amalgama que después: entre 1501 y 1562 los precios al consumo crecieron al 1,87 por 100 anual, para desacelerarse hasta el 1,24 por 100 entre 1562 y 1600 , y volver a la deflación en el primer tercio del siglo siguiente, durante el que experimentaron una tasa negativa de $-0,2$ por 100 entre 1600 y 1635 (Reher-Ballesteros, 1993). De la relación entre las llegadas acumuladas de metal americano y los precios, representada en coordenadas semilogarítmicas en el Gráfico 1, se deduce que entre $1516-20$ y $1631-35$ la varianza de los promedios quinquenales de estos últimos se explicaría en un 98,6 por 100 por la del stock acumulado de oro y plata llegado a Sevilla — como prevé la teoria monetaria-, pero la elasticidad logarítmica de los precios castellanos respecto a las entradas acumuladas de metales preciosos sólo fue 0,31 (la duplicación del stock provocó un crecimiento del 31 por 100 en los precios) ${ }^{1}$. Así pues, la lógica económica avala la tesis de Flynn y Giráldez (2000), según la cual el factor fundamental para explicar conjuntamente la ausencia de inflación durante el siglo XV europeo, la moderación en el crecimiento de los precios durante el siglo XVI, la caída de los precios-plata durante el XVII y el escaso impacto

${ }_{1}^{1}$ Hasta 1620 las cifras de metales son de Hamilton (1934, p. 47). Entre 1621 y 1675 , de Alvarez Nogal (1998, pp. 486-487). Los precios de Castilla la Nueva son de Reher y Ballesteros (1993). La producción de plata acumulada se calcula con el mismo método del Cuadro 3. 


\section{GRÁFICO 1 \\ Castilla la Nueva. Índices de precios y de metales \\ $(1601-1625=100)$}

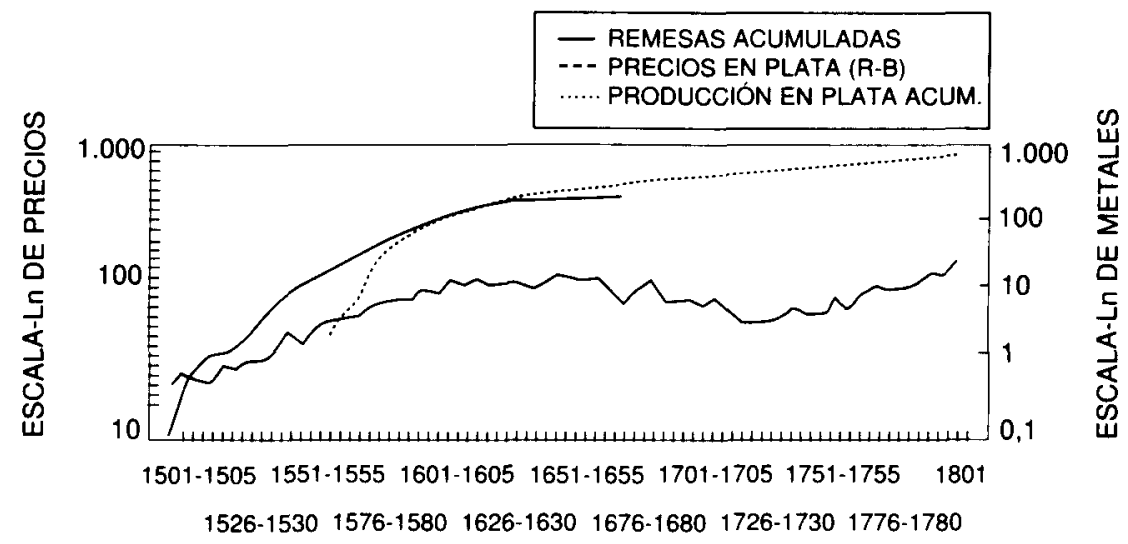

inflacionista de la riada de plata mexicana del xvin fue el brusco aumento del nivel del comercio intercontinental de plata, porque aproximadamente la mitad de la plata americana no llegó a circular en Europa (Gráficos 1 y 4).

En este trabajo no aporto evidencia empírica nueva. Trato simplemente de revisar la explicación tradicional, que atribuye al azar el ascenso de la monarquía de España a la condición de primera potencia universal. $\mathrm{O}$, más bien, pretendo reconfigurar el argumento, haciendo descansar la centralidad de la explicación sobre las consecuencias de la formación del primer mercado global de metales monetizables. En la primera parte del trabajo un sencillo diagrama permite relacionar la explosión de la oferta agregada con la demanda de dinero, explicada esta última por la oferta real, la política militar y la demanda de metal en el mercado asiático.

La conjunción de estos factores explica la inexpugnable ventaja monetaria comparativa de que disfrutó la monarquía de España durante siglo y medio, apoyada sobre una sencilla, pero muy eficiente, combinación de las políticas mineras de la plata y el cinabrio en América y del azogue en Almadén —que se estudian en la segunda parte-, y en el aprovechamiento de la relación de intercambio bimetálica (oro/plata) entre los dos extremos de Eurasia, que a finales del siglo xvi guardaba, como mínimo, 
una relación de uno a dos: entre 1:5,5 y 1:7 en China, y entre 1:12,5 a 1:14 en España ${ }^{2}$. El imperio sirvió de puente entre esos dos polos del sistema monetario global, lo que dotó de un valor inestimable a Filipinas - con el Galeón de Manila- y a la unión con Portugal, que garantizaba una conexión directa con China por la vía oriental.

Estas políticas se explican por los «empleos» a que iba destinado aquel recurso, el más preciado de los cuales no era económico, sino acrecentar el poder político internacional del monarca. Esto requería ejércitos expedicionarios, cuyas soldadas se pagaban exclusivamente en oro durante el siglo XVI, puesto que sólo a comienzos del Xvi los tercios empezaron a admitir plata (Álvarez, 2000). En todo caso, el oro fue siempre el «dinero político» por excelencia (Ruiz Martín, 1990) y la mayor parte se traía de Extremo Oriente, a cambio de plata, y como forma de repatriación de los beneficios del comercio intracontinental de los europeos, ya que la producción de oro estimada por Humboldt $-\mathrm{y}$ confirmada por TePaske (1998) - sólo representó el 10,2 por 100 del valor de los metales preciosos producidos en las colonias americanas de España. En conjunto, durante los siglos XVI y XVII el oro americano no supuso más que el 15 por 100 de la producción mundial.

Como la producción de plata dependía de la de azogue y ésta fue siempre monopolio de la Corona — sin otra posible competencia que la de las minas de Idria y Carintia, controladas por la otra rama de la casa de Austria-, el azogue constituye «el coeficiente del estado económico de la península» (Lang, 1998) y su coyuntura productiva refleja, mejor que ningún otro indicador, la evolución de los mercados monetarios mundiales y de las necesidades de financiación de la monarquía, dada la estabilidad de la relación de productividad entre cantidad de azogue y de plata, y la dependencia del crédito de la monarquía —y, en general, de todo el comercio exterior español y europeo- respecto al saldo en plata de la balanza de comercio con las colonias. La tercera parte pone de manifiesto la continuidad en la política de azogue - y de plata-, como característica distintiva de la España moderna. Un último epígrafe sintetiza brevemente el argumento y concluye.

${ }^{2}$ La relación española creció constantemente desde un mínimo de 1:10,1 en 1497 a un máximo de 1:15,5 en 1643 (Munro, 1999b). En Oriente, en 1620 la relación china era 1:8 y la japonesa 1:13 (Miyamoto y Shikano, 1998, p. 138). 


\section{LA OFERTA MONETARIA, VARIABLE ENDÓGENA}

Frente a la idea de Cipolla acerca de los golpes de fortuna, los trabajos de Matilla Tascón sobre las minas de Almadén indican que la producción de azogue para el beneficio de la plata fue cualquier cosa excepto una variable con comportamiento exógeno, debido al azar. $\mathrm{O}$, más bien, el tránsito por la tenue frontera que separa azar de necesidad fue, en este caso, la lógica del mercado (Gráfico 2$)^{3}$. Por el contrario, aun en ausencia de la «hipótesis china», la introducción de la amalgama en 1554-1557, cuando los precios en Castilla la Nueva estaban creciendo a ritmo más fuerte $-\mathrm{y}$, por tanto, la plata se estaba desvalorizando en términos relativos-, pero coincidiendo con el momento en que el Emperador afrontaba sus mayores agobios financieros - y aumentaba la demanda de «dinero

\section{GRÁFICO 2}

Azogue enviado y total de plata.

Medias móviles quinquenales centradas ( $T m$.)

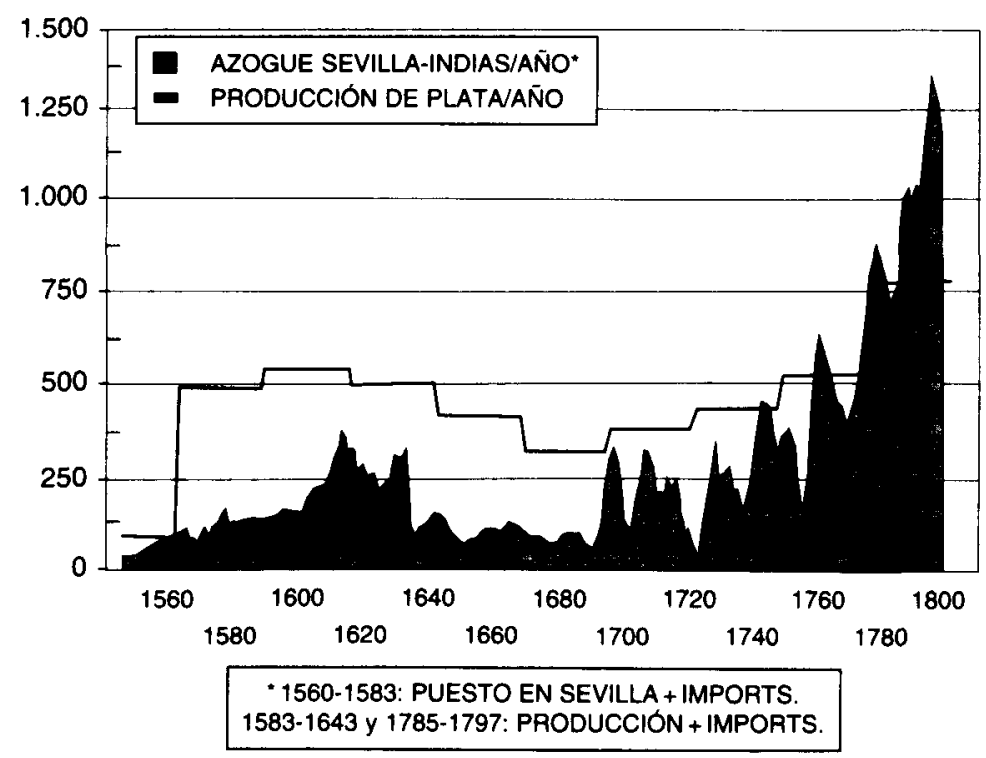

${ }^{3}$ Los datos sobre azogue para construir el Gráfico 2 provienen de Matilla Tascón: I (1560-1645), pp. 80, 98, 106-107, 110-111, 121, 122, 137, 171, 182, y II (1646-1799), pp. 97, 104-105 y 354-356. Los de la plata, tanto en éste como en los Gráficos 3 y 4 , son los del Cuadro 3. 
político»-, podía considerarse como la mejor prueba de la endogeneidad de la oferta de dinero.

Ahora bien, en un sistema con moneda metálica de pleno valor intrínseco y acuñación relativamente libre - con costes de transformación e impuesto de señoreaje-, este carácter endógeno debe entenderse en términos relativos, relacionándolo con los costes de producción del metal: esto es, si la rigidez de la oferta de productos consumibles era superior a la de la producción de plata, la posibilidad de obtener un beneficio extraordinario en el mercado del metal consistía precisamente en introducir innovaciones y en mejorar la productividad, respondiendo a la caída relativa de valor de mercado de la plata con un movimiento de tijeras. El asunto no era especialmente complicado desde el punto de vista técnico, puesto que las propiedades del azogue en el beneficio de la plata se conocian desde los romanos y la técnica de la amalgama ya se venía usando para usos industriales en Alemania —que había alcanzado antes que América el punto de equilibrio entre costes de producción y precios de mercado, y producía cada vez menos plata-, de modo que de lo que se trataba era de adoptar una nueva técnica, no de inventarla. El propio Medina se autocalificaba de broker tecnológico: «Yo soy el que dí la industria de cómo se sacase la plata con el azogue» (Matilla, 1987, I). Que lo que ocurrió se inserta en la más pura dinámica de mercado lo demuestra la carta de los oficiales reales en Nueva España de 31 de diciembre de 1554, en la que se afirmaba:

«Aquí vino hace poco tiempo un Bartolomé de Medina, vecino de Sevilla, que dijo traer consigo a un alemán, al que no dejaron pasar acá, que sabe beneficiar los metales de plata con azogue a gran ventaja de lo que acá se hace y sabe; y de lo que de él tomó ha hecho experiencia, por donde parece sería gran riqueza la venida del alemán si hubiese azogue. Mande V. Mgd. que venga, y se traiga cantidad de azogue, que por cierto se tiene que la renta que acrecentará en un año a V. Mgd. valdrá más de lo que ahora valen seis; $y$ este negocio es de gran calidad [...].»

Ante las constantes demandas de fondos llegadas de la Corte, la carta de los oficiales de la monarquía indicaba que la nueva técnica podía multiplicar por seis los ingresos de la Hacienda en Nueva España. Se trataba, pues, de un negocio estratégico, puesto que de la cantidad de azogue iba a depender la extracción de plata y de ésta el volumen de los quintos y diezmos reales, única fuente de la que se podía enviar dinero de América al Rey, «ya que todos los demás recursos reales se necesitan para la costa 
y sustentación de estos reinos» (Matilla, 1987, I). En 1557 esos mismos oficiales darían una explicación completa del agotamiento del margen de arbitraje entre el valor de mercado y el coste de explotación de la plata mediante las técnicas tradicionales:

«[...] que venga el alemán u otros alemanes [...] por la gran abundancia de metales que tienen [plata] en toda esta tierra [...] por estar muchos en parte que si no es con azogue no se pueden beneficiar de otra manera, así por falta de montes, como de bastimentos, por la mucha gente, leña y carbón que es necesario para sacarla por fundición; y la ley de los metales no sufre tan grandes gastos, y no se puede sacar por fundición si no es costando más que el valor de la plata que se saca; y con el azogue hácese a gran ventaja».

Esto es: los agentes del rey pensaban que, si no se conseguía desplazar rápidamente la función de producción de la plata (y de oferta de especies metálicas monetizables) hacia la derecha, los rendimientos decrecientes terminarían por frenar la expansión o hacer decaer la producción. La demanda de dinero venía determinada, en el ámbito continental: a) por la oferta agregada de la economía europea, que, al ser predominantemente agraria, soportaba rendimientos fuertemente decrecientes; $b$ ) por la demanda directa de «dinero político», y $c$ ) por la capacidad de canalizar partidas hacia China a través del lucrativo comercio con Oriente. Por su parte, la oferta de dinero actuaba como contrapartida de la demanda agregada real: a) de productos y servicios para consumo e inversión por parte de la población y de las unidades de explotación; $b$ ) del saldo de la balanza de comercio con América, y $c$ ) de la demanda de aparato bélico por parte de los monarcas. Todas estas fuentes y empleos resultaban competitivos entre sí.

En el diagrama, la oferta agregada real (que constituye sólo uno de los componentes de la demanda de dinero) se representa mediante una curva con un tramo de rendimientos constantes y otro de rendimientos decrecientes. Siendo $\mathrm{P}$ el nivel general de precios y $\mathrm{Q}$ la demanda efectiva real, las demandas agregadas nominales en los puntos $\mathrm{E}$ y $\mathrm{E}^{\prime}$ equivalen a las superficies de los rectángulos OAEC y OBE'D, que son directamente proporcionales a la cantidad de numerario disponible ( $\left.M \circ \mathrm{M}^{\prime}\right)$ e inversamente proporcionales a la «demanda de saldos de caja» ( $k$ o k'). Esta magnitud es la inversa de la velocidad de circulación, de modo que crece con el «efecto riqueza» de Patinkin, como sucedió en España (González y Del Hoyo, 1983), y decrece con el desarrollo del sistema de crédito y la innovación financiera, lo que en el conjunto de Europa se tradujo 


\section{DIAGRAMA}

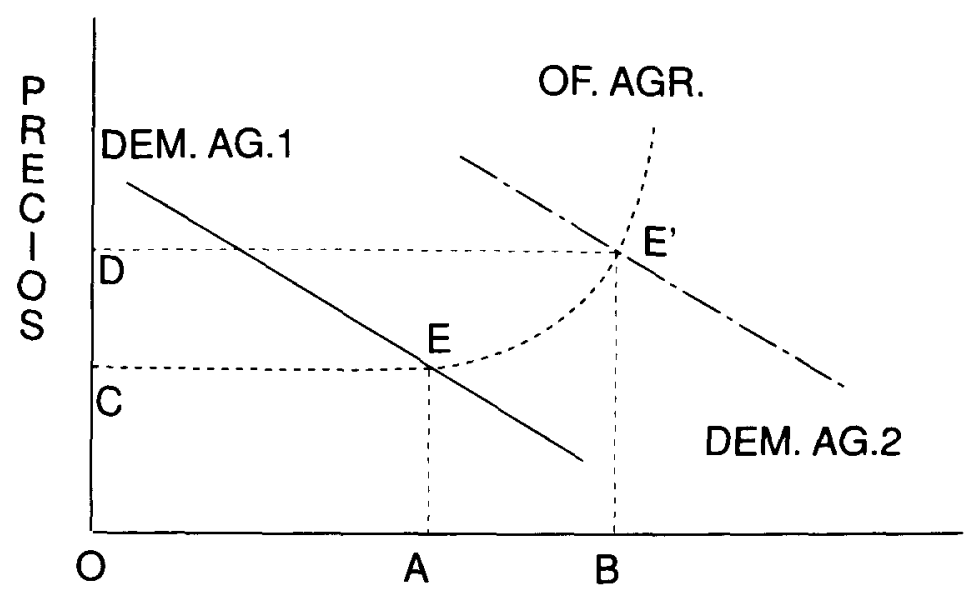

CANTIDADES

OAEC $=P \cdot Q=M / k$
$O B E \cdot D=P^{\prime} \cdot Q^{\prime}=M^{\prime} / k^{\prime} \Rightarrow k^{\prime}<k$

en una reducción del 50 por 100 en el tipo interés durante la primera mitad del siglo XVI (Munro, 1999b), mientras en España el tipo de interés de los juros al quitar se reducía sólo en un 37,5 por 100 (Espina, 2001b). La baja elasticidad de los precios-plata que se infería del Gráfico 1 no tiene reflejo en el diagrama porque buena parte de la masa monetaria americana (aproximadamente la mitad de la plata registrada, como veremos) no circuló en Europa, sino en China. Y con mayor motivo cabe hablar de la falta de equivalencia entre remesas metálicas y circulación monetaria en España. La fuerte caída de los tipos de interés, sin embargo, indica que la reducción del coste de producción y la mayor velocidad de circulación de la plata - respecto al oro-, así como el desarrollo del crédito, prevalecieron sobre el efecto riqueza, haciendo $k^{\prime}<k$, de modo que durante el siglo XVI el crecimiento de la demanda agregada pudo resultar superior al de la oferta monetaria efectiva. Poco se puede decir del siglo xvI, porque el tipo de interés quedó intervenido, la moneda manipulada por el monarca y el mercado financiero destruido. 


\section{LA POLÍTICA INDUSTRIAL Y LA PRODUCCIÓN DE PLATA Y AZOGUE}

El método de Medina consistía, según Alonso Barba, en moler o triturar el mineral de plata, humedecerlo, extenderlo en patios enlosetados y mezclarlo con sal común («magistral») y azogue («mercurio») con la ayuda de caballerías; luego se metía en grandes tinas, en donde la mezcla era apisonada por los indígenas con los pies descalzos, y se lavaba para separar la amalgama de los elementos no metálicos; finalmente, se calentaba la mezcla para evaporar el mercurio, recuperando parte de él, y se retenía la plata, filtrándola entre dos lienzos bien tupidos.

No existe una interpretación química moderna de la descripción de Barba. Humboldt (1991) pensaba que la mezcla de mineral de plata (Ag) con sal ( $\mathrm{ClNa}$ ) producía cloruro - muriato - de plata (ClAg), que se amalgamaba directamente con el mercurio. Su descripción olvida que los minerales más abundantes en México - pacos, o colorados (o sea, cerargirita) - son cloruros de plata. Por eso, el mejor químico de la época de Humboldt, José Garcés, destinaba el muriato de plata a la fundición, mezclándolo con carbonato de sosa natural $\left(\mathrm{CO}_{3} \mathrm{Na}_{2}\right)$, o tequestite, para reducir oxígeno, liberar dióxido, formar sal y dejar libre la plata $\left(\mathrm{CO}_{3} \mathrm{Na}_{2}+2 \mathrm{ClAg} \Rightarrow 2 \mathrm{ClNa}+\mathrm{CO}_{2}+\mathrm{O}+2 \mathrm{Ag}\right)$. Medina amalgamaba en frío y al aire. Con las «lamas» de mineral en polvo lavado formaba una torta de barro. El agua para amasarlo contenía, seguramente, grandes cantidades de sosa natural, ya que las corrientes que bajaban de las montañas venían saturadas de ella, hasta el punto de que, según Humboldt, «la llanura central de Asia no es más rica en sosa que México». Esto es lo que habría permitido a Medina dar con su método por simple prueba y error («por fortuna»). Si el barro contenía abundante hidróxido sódico $(\mathrm{NaOH})$, al mezclarse con el mineral produciría agua y sal común, la plata quedaría libre para la amalgama y el oxígeno oxidaría las impurezas metálicas $\left(4 \mathrm{NaOH}+4 \mathrm{ClAg} \Rightarrow 4 \mathrm{CINa}+\mathrm{O}_{2}+2 \mathrm{H}_{2} \mathrm{O}+4 \mathrm{Ag}\right)$. Esto implica que en la amalgamación por patio se producía sal, aunque, siguiendo la tradición alemana, también se le añadiese en gran cantidad, para que la reacción en medio alcalino evitase la formación de ácido clorhídrico $(\mathrm{ClH})$, como se hace actualmente en la cianuración. Con el tiempo, dependiendo del tipo de mineral, los azogueros aprenderían a regular el proceso («curtirlo»), añadiendo cal para «enfriar» la masa, o sulfatos metálicos (a los que denominaron «magistral») para calentarla.

A la vista del cuadro de acciones y reacciones en los diferentes mercados, hay que concluir que la flexibilidad de la respuesta a la introducción 
de la amalgama fue impresionante. Las expectativas despertadas tardaron en materializarse por la escasez de azogue tras el incendio de la mina de Almadén, que obligó a importarlo, al menos hasta la regularización del suministro en 1564 (Matilla, 1987, I), año en que Amador de Cabrera registró también el descubrimiento de la mina de azogue «Descubridora», en Huencavélica, tras un decenio de intensos esfuerzos por parte de las autoridades virreinales para impulsar la explotación de este mineral (Lohmann, 1949, cap. 1), cuyos precios de mercado aumentaron casi con carácter simultáneo a la difusión de la amalgama. En el arriendo a los Fúcar entre 1547 y 1550 la Corona se lo había comprado a 9 o 10 ducados el quintal (de cuatro arrobas, o 46 kilogramos) y lo había vendido a 20 . Tras el incendio de 1550, la mina de Almadén había quedado inactiva, pero las cartas de los oficiales de Nueva España aconsejaron acelerar los trabajos de restauración, ya que en 1556 el precio del quintal de azogue había subido a 25 ducados. Entre 1557 y 1562 se encargó al gobernador Ambrosio Rótulo el restablecimiento de la producción, mientras el precio de mercado del azogue pasaba desde 32 a más de 85 ducados el quintal en la Península, lo que aconsejó realizar asientos para importarlo - a precios entre 20 y 25 ducados- e impulsar la explotación de las minas de azogue descubiertas por Enrique Garcés en Perú y Ramírez Dávalos en Quito, entre 1558 y 1559 , antes de la adopción del método de la amalgama en las minas de Potosí, que la Corona había tratado de impulsar sin éxito desde 1555, pero que sólo se haría imprescindible tras el agotamiento del mineral más rico - la «tacana»- a partir de 1566, para beneficiar de forma rentable los minerales pobres (Lohmann,1949)

Los beneficios extraordinarios derivados de esta dinámica aconsejaron declarar el estanco del azogue en 1559. Tras un quinquenio de restauración y explotación directa de la mina de Almadén, durante el que se importó azogue, se celebró el primer asiento con los Fúcar (1563-1572) para acelerar la extracción y garantizar la remisión a gran escala de mineral hacia las Indias. El escaso rendimiento de las minas de Perú y Quito desaconsejó aplicar allí el estanco hasta la Provisión de 5 de febrero de 1564 -tras el descubrimiento de Huencavélica - que estableció la regalía de la Corona. En 1568 se ordenó al virrey Toledo aplicar en Perú el modelo de asiento suscrito con Fúcar en Almadén (Lohmann, 1949), pero la medida sólo avanzaría tras el fallo del Consejo de Indias de 14 de noviembre de 1571, que concedió a Cabrera la explotación a cambio de entregar a la Corona el 66 por 100 de sus beneficios en especie. El momento coincide con la introducción de la amalgama en Potosí por Pedro Fernández de Velasco, 
que importó el procedimiento desde México, donde había sido fundidor, modificando el método de patio para adaptarlo a las características y la consistencia de la plata y el azogue peruanos, que no habían permitido hasta entonces difundir y generalizar la amalgama, conocida allí desde 1559. Sólo a partir de esta adaptación - reconocida por derecho de patentese produjo la «resurrección» de Potosí y el «matrimonio» entre su cerro y el de Huencavélica permitió triplicar la producción de plata entre 1571 y 1572.

Durante el primer decenio de asiento en Almadén, los Fúcar entregaron 13.100 quintales a un precio convenido entre 25 y 29 ducados -aunque con los intereses de demora subieron a 34,7 (Matilla, 1987, I) - que se estaban cediendo en 1563 al beneficiario del monopolio de venta —un tal Juan Núñez - al precio de 100 ducados el quintal —si bien en venta directa la corona lo cobraba a 120 - intermediarios que se resarcian vendiéndolo en Nueva España en almoneda a precios entre 180 y 190 pesos de minas. Como el peso de minas o real de a ocho (R.8) equivalía a 272 maravedís, el precio final se situaba entre 130,6 y 137,8 ducados (de 375 mavds.). Por su parte, a partir de 1571 Huencavélica triplicó su producción, aunque ésta no superó los 2.500 quintales/año mientras pudo beneficiarse en «lavaderos» el cinabrio más rico. El bajo coste de producción de este procedimiento redujo la cotización del azogue peruano a 40 pesos en 1573, año en que se suscribió el primer asiento con los mineros «concesionarios», por el que el Estado iba a adquirir anualmente 1.500 quintales de azogue, a un coste bruto de 51,4 ducados - 41,1, una vez descontado el quinto real- La cantidad anual se elevaría a 9.000 quintales en el segundo asiento, suscrito en 1577, que se complementó con otro para portear el azogue hasta Potosí, por el que la Corona lo entregaba a 78,3 ducados y los asentistas lo vendían en Potosí a 104 ducados (o 108 y 143,4 pesos-Rs.8, respectivamente).

Quince años antes (el 15 de junio de 1558) el factor de los Fúcar en Nueva España, Cristóbal Réiser, señalaba que el azogue se pagaba allí a 150 ducados (frente a 60 que había venido siendo su precio normal), porque «sin azogue, poca plata se obtiene en las minas» (Carande, 1987, 2). Frente a estos precios de venta, en el Gráfico 3 se ha estimado la evolución del coste medio de producción del quintal de azogue -incluidos los portes de Almadén a Sevilla, pero no a Indias - para cada cuarto de siglo y las cantidades de azogue entregadas en Sevilla, todo ello a partir de la información recogida por Matilla Tascón. 


\section{GRÁFICO 3}

Plata y coste/volumen de azogue.

Media ponderada y disponibilidades por periodo

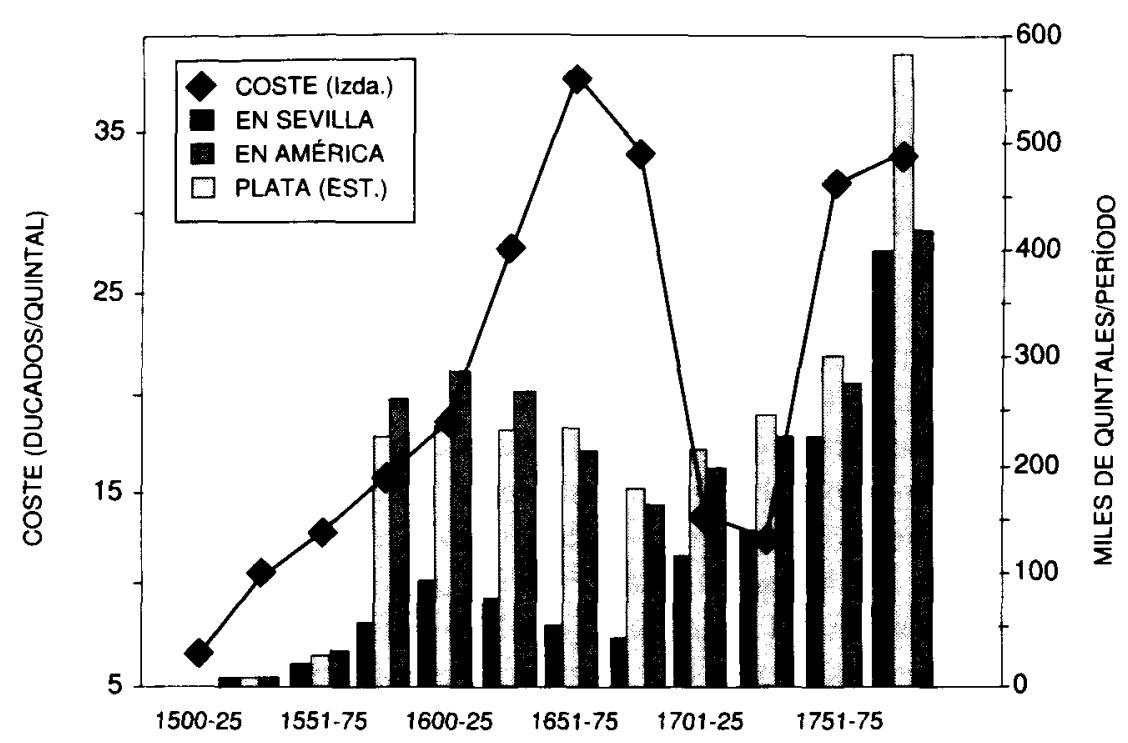

En el cuadro 1 se trasladan estas cifras a toneladas métricas. Lo más significativo de estos datos es el movimiento paralelo de costes de extracción y volumen de producción durante los siglos XVI y XVII, y un movimiento de tijeras durante el siglo xvi que está relacionado con las economías de escala de la producción, dada la relación entre el volumen de la demanda de dinero y la oferta agregada y la interacción entre los mercados monetarios y reales. A partir de mediados del siglo xv la serie construida en el cuadro 2 por agregación de la producción de azogue de Almadén puesta en Sevilla más la de Huencavélica — recogida por Humboldt en los archivos de la Tesorería - y una vez añadidas las importaciones de Austria, constituye probablemente el mejor indicador de la producción registrada de plata, y al mismo tiempo el principal elemento regulador de la misma.

En efecto, en torno a 1560 don Fernando de Portugal, tesorero de Nueva España, calculaba que de 2.500 quintales de azogue se podrían sacar 2.000 de plata, con una relación de 1,25:1, muy parecida a la estimada por el oidor Moreto en Lima en 1666: 100 quintales de azogue por 81 


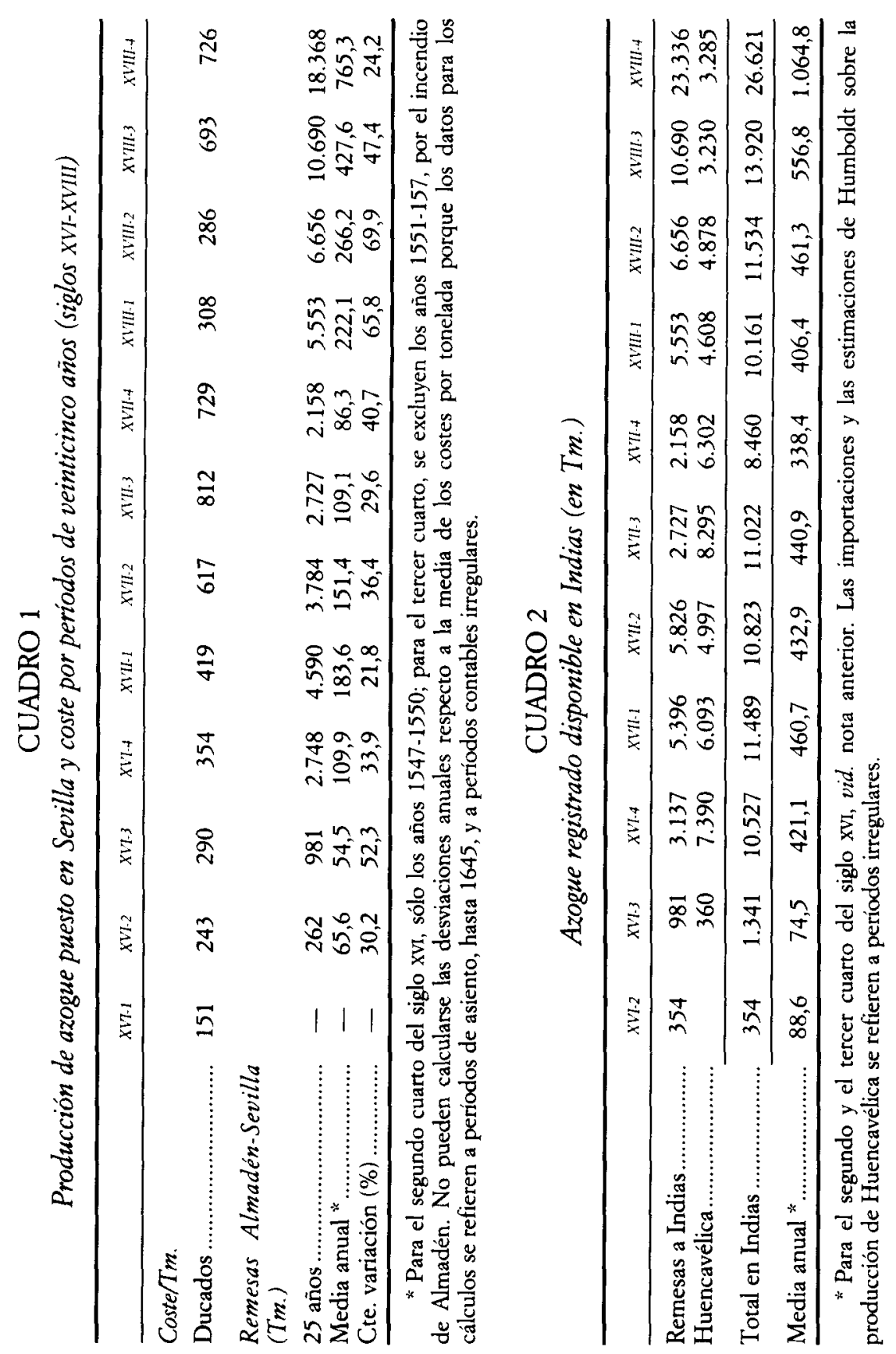


de plata. Para el licenciado Álvaro Alonso Barba, cura párroco de S. Bernardo en Potosí y seguidor de Raimundo Llull, sólo el más diestro beneficiador consumía en el «cajón» (equivalente peruano del patio) «por lo menos, otro tanto azogue como saca de plata». Alejandro de Humboldt (1991), en su viaje a Nueva España por cuenta de la Corona en 1801, consideró que en las minas de Guanajuato -que seguían empleando el método de Medina de la «amalgamación por patio», como se hacía en todo el continente, se consumían $1,6 \mathrm{~kg}$. de mercurio por cada kilogramo de plata producida, ocho veces el mercurio empleado en Sajonia mediante el nuevo método, introducido por Geller y Charpentier, ipero mientras en Freiberg se beneficiaban al año 60.000 quintales, en Nueva España eran más de diez millones, y no habría toneles, ni fuerza motriz, ni leña suficientes para copiar el método alemán! Ya en 1778 Friederic Sonneschmidt, miembro de la expedición científica de Fausto Delhuyar, había intentado introducir en México el método de barriles de Born —a su vez, inspirado en el Tratado de Alonso Barba-, pero obtuvo un rendimiento mínimo y se abandonó (Lang, 1977, y Castillo-Lang, 1995).

A estas dificultades objetivas habría que añadir la política de la Corona, que impidió la diversificación tecnológica y la innovación productiva para mantener el control fiscal y el sistema burocrático de exacción de rentas: en 1571 se prohibió extraer plata por el método de fundición, y en 1588-89 se prohibió taxativamente el «invento» de los hermanos Corso de Leca -descrito por Alonso Barba- que utilizaba un magistral mezclado con escorias de hierro y reducía a una cuarta parte el consumo de azogue, denegándose toda licencia que solicitase autorización de emplearlo, no obstante lo cual muchos mineros debieron de hacerlo, lo que explicaría la brusca caída de la demanda de azogue a partir de 1590. Esta política de subordinación de la innovación a la simplicidad fiscal debió de impulsar la aparición de un cierto número de explotaciones no registradas - ni registrables- que fueron pieza básica para el contrabando en la producción de plata, ya que el avance en las técnicas del beneficio del metal —con ahorro de azogue - permitió ampliar paulatinamente el tipo de mineral utilizado, beneficiándose plata en desmontes antiguos, extraída de vetas profundas - con alto coste de manipulación- $\mathrm{e}$ incluso reaprovechando «lamas y relaves» (Alonso Barba, 1640).

Durante el medio siglo siguiente estas posibilidades no dejaron de aumentar debido a la impresionante mejora de las técnicas metalúrgicas y su adaptación a las condiciones geográficas y a las existencias de mineral 
peruano ${ }^{4}$. Alonso Barba las sintetizó en su Arte de los Metales (1640), atribuyendo al alto contenido de «caparrosa» del mineral más abundante en Perú (una pirita, denominada «negrillo») tanto el fracaso de los primeros intentos de utilizar la amalgama, como la elevación del rendimiento del azogue utilizando escorias de hierro. Su razonamiento para explicar el llamado «beneficio de hierro» resulta perfectamente trasladable a los conceptos de la química y la minería modernas: la caparrosa (kupferashe; en aimara: copaquira) son sulfatos hidratados de cobre o de hierro (vitriolos azul y verde, solubles: $\mathrm{SO}_{4} \mathrm{Cu} \cdot 5 \mathrm{H}_{2} \mathrm{O} ; \mathrm{SO}_{4} \mathrm{Fe} \cdot 7 \mathrm{H}_{2} \mathrm{O}$ ). Como el «negrillo» es sulfuro de plata (argentita) con caparrosa, una vez molido, antes de incorporarlo al «cajón» había que lavarlo para eliminar los sulfatos. Además, las piritas se enriquecen agregando limaduras de un metal (hierro o cobre) más activo que el radical del sulfuro (la plata), para que lo sustituya, formando sulfuro de hierro y liberando la plata $\left(2 \mathrm{SAg}_{2}+\mathrm{Fe} \Rightarrow \mathrm{S}_{2} \mathrm{Fe}+4 \mathrm{Ag}\right)$, que se mezcla con el mercurio en la amalgama. Del mismo modo, cuando durante la amalgama se forma sulfato mercúrico $\left(\mathrm{SO}_{4} \mathrm{Hg}\right)$, el hierro o el cobre sustituyen al mercurio como radical y forman sulfato férrico o de cobre, o sea, caparrosa, liberando de nuevo el mercurio ${ }^{5}$.

En Huencavélica —como sucedería también más tarde en Nueva España- los agobios fiscales de la Corona descompusieron en seguida el mercado, lo que condujo a la aparición de un fluido sistema de contrabando de azogue, ya que, al no cumplir la Tesorería los compromisos de anticipo de fondos establecidos en los asientos - ni abonar el resto al hacerse las entregas-, la acumulación de atrasos obligaba a los mineros a dejar de entregar azogue y a venderlo directamente a los defraudadores («aviadores») - incluso con pérdidas - para evitar tener que abonar intereses usurarios. El sistema se complementaba con el contrabando de los asentistas porteadores —en ciertos casos miembros de la burocracia virreinal-, que llegaban a suscribir asientos en pérdidas porque el azogue ilegal se compraba una tercera parte más barato que el oficial -y en ocasiones a la tercera parte de su precio- y se vendía en Potosí una tercera parte más

${ }^{4}$ Potosí está a una altitud de 5.000 metros. La menor presión atmosférica retrasa mucho el proceso químico. La explicación científica sería aportada por Sonneschmidt (Castillo y Lang, 1995, pp. 101 ss.). La modificación del método de Medina para introducirlo en Perú se realizó en 1571 por prueba y error.

${ }^{5}$ El sistema peruano del «beneficio de hierro» fue introducido por Gellert en Sajonia y su máxima eficiencia verificada experimentalmente por Gay-Lussac y Humboldt en 1804 (1991, p. 380). El sulfato de mercurio y la sal sólo pueden mezclarse en frío, ya que en caliente producen cloruro mercúrico («sublimado corrosivo»), muy venenoso: $\mathrm{SO}_{4} \mathrm{Hg}+2 \mathrm{ClNa} \Rightarrow \mathrm{Cl}_{2} \mathrm{Hg}+\mathrm{SO}_{4} \mathrm{Na}_{2}$. 
caro, por ir destinado a la producción de plata sin pagar el quinto real. Ya a mediados de los años ochenta del siglo xvi se estimó que se transportaban tres mil quintales de azogue de matute al año, equivalentes a la tercera parte de los 9.000 quintales legales (Lohmann). La inseguridad en los pagos explica que los mineros no retuviesen los beneficios, que pasaban a los aviadores. Como la prosperidad de esta clase dependía de una actividad irregular, se limitaban a proporcionar financiación usuraria a corto plazo, lo que explica la infrainversión de las explotaciones y su agotamiento prematuro. Sólo tras las reformas de Gálvez, que incentivaron la reinversión en las minas del capital de los hacendados mexicanos y de los comerciantes - una vez perdida la renta monopolista por parte de éstos-, la minería de Nueva España rompió el círculo vicioso y experimentó el impresionante boom de finales del siglo xvIII (Castillo y Lang, 1995; Fisher, 1998).

En cualquier caso, aquellas estimaciones casan difícilmente con la de 150.000 toneladas de plata extraídas en el continente durante todo el período colonial realizada por Flynn y Giráldez (1996). La información de Matilla sobre la producción de azogue en Almadén, que es la fuente más firme de que se dispone, permite estimar en 58.516 toneladas la cantidad total de azogue producido entre 1547 y 1799 (Cuadro 1). A la plata beneficiada con el azogue de Almadén hay que añadir: el tesoro inicial —escasamente significativo- y la extracción de plata por procedimientos anteriores o distintos de la amalgama; el de las minas alemanas de Idria y Carintia — cuyas remesas no superaron las $3.250 \mathrm{Tm}$. hasta 1645 y sólo se hicieron regulares desde 1785, aportando entre ese año y 1797 en torno a $5.000 \mathrm{Tm}$.- Como el total de remesas oficialmente exportadas a América fue algo menos de $67.000 \mathrm{Tm}$., agregándoles las $49.000 \mathrm{Tm}$. de azogue de Huencavélica las disponibilidades totales de azogue legal ascendieron a $116.000 \mathrm{Tm}$. (Cuadro 2), cantidad con la que pudieron producirse entre 93.000 toneladas de plata (ratio $1,25: 1$ ) y 73.000 (ratio $1,6: 1$ ); o sea, una cantidad promedio de $83.000 \mathrm{Tm}$. La ratio efectiva entre cantidades registradas de azogue y plata debió de encontrarse en ese intervalo, ya que durante el siglo XVIII la relación media oficial entre plata producida y disponibilidades de azogue fue de 1,29, pasando de 1,02 en $1717-1739$ a 1,75 en $1779.1796^{6}$.

${ }^{6}$ Los períodos de veinte años son los de García-Baquero (1998). Se estima, con este mismo autor (1996), que las remesas suponen un 62 por 100 del total de lo producido, al que se le ha restado la producción de oro (TePaske, 1998, Tabla 2). Para los cuatro 
Cipolla (1999) admite como cantidad de plata oficialmente extraída en América durante los tres siglos la estimación de unas $82.000 \mathrm{Tm}$. hecha por Morineau (2000), quien considera al mismo tiempo que un tercio de esta cifra habría sido reexportada de Europa a China y un sexto enviada alli directamente desde Acapulco (13.667) a cambio de seda, cifra no muy distante de la finalmente propuesta por Flynn y Giráldez (2000) al admitir un máximo de extracciones directas hacia Oriente de $55 \mathrm{Tm}$. (dos millones de reales de a ocho) al año durante 225 años (12.375 $\mathrm{Tm}$.).

La cifra de envíos a Filipinas equivale al 17 por 100 de la producción oficial de plata americana en el siglo xvil. La ruta comercial entre Japón y China la habian abierto los comerciante chinos y portugueses entre 1560 y 1600, trasvasando anualmente de 34 a $49 \mathrm{Tm}$. de plata, a cambio de seda (Prakash, 1998). A ello se unieron después los holandeses, que acudieron a las Indias Orientales en busca de especias. Pero el archipiélago indonesio, que disfrutaba del monopolio natural de éstas, no quería plata, sino tejidos indios baratos, de modo que se inició un comercio cuadrangular, o, más bien, «browniano» (Landes, 1999). El Galeón de Manila, al diversificar el suministro de plata, vino a completar el negocio de chinos, portugueses (hasta 1639, en que éstos fueron expulsados de Japón) y holandeses, cuya escasa vocación evangelizadora les permitió alzarse con el monopolio europeo del comercio japonés hasta 1853 (Maddison, 2001). La renta de este tráfico permitió a la Corona española financiar la guerra contra los holandeses en Oriente (Flynn-Giráldez, 1998). A su vez, la repatriación de beneficios en forma de oro proporcionó el «dinero político» en que se basó el negocio de Lisboa y Amsterdam como centros financieros de los Austrias.

A la plata registrada hay que añadir la estimación de la producción ilegal. Como el azogue extraído de contrabando de Huencavélica pudo ascender a $16.333 \mathrm{Tm}$., a una tasa de rendimiento medio debió de producir en torno a $11.500 \mathrm{Tm}$. Suponiendo también un tercio de contrabando en México, la cifra de plata producida pudo ascender a $110.000 \mathrm{Tm}$. Humboldt estimó una producción total, incluido el contrabando, entre 1492 y 1803 de $118.000 \mathrm{Tm}$. (4.358,2 millones de pesos Rs.8, o sea, 512,7 millones de marcos, ademas de 493 millones de pesos en oro, equivalentes

períodos, las ratios fueron: 1,$02 ; 1,2 ; 1,05$, y 1,75 . La elevación de la ratio al final del siglo -observada por Humboldt-, es fruto de la politica de bajos precios y menor fiscalidad para fomentar la producción y de la más eficiente explotación en Nueva España, fruto de la inversión, que permitió explotar a mayor profundidad, lo que en todas las minas de América significaba menor riqueza mineral. Vid. Castillo y Lang, pp. 56-59, 65 y 128-132. 
a $834 \mathrm{Tm}$.), pero basó sus cálculos sobre la cuantía de la plata quintada, sin aplicar correcciones por las múltiples exenciones existentes, que alcanzaron hasta el 15 por 100 (Bernal, 2000). La cifra de $110.000 \mathrm{Tm}$. implica unas exenciones medias del 7 por 100 .

En el cuadro 3 esta cifra se distribuye por períodos en función del azogue disponible, suponiendo rendimientos oficiales de 1:1 hasta 1650 ; de 1,25:1 hasta 1775 , y de 1,6:1 en el último cuarto del siglo Xvil. El cuadro refleja también las remesas de plata por período (vid. nota 1).

El 62 por 100 de la producción oficial pasaba a España (García-Baquero, 1996) y el resto entraba directamente en circulación, mientras que la plata de contrabando «se embarcaba subrepticiamente en la Armada y, yendo fuera del registro, eludía el pago de la avería, tanto en la mar del sur como en el Atlántico. Finalmente, tampoco entraba en territorio español, por las graves penas que castigaban este tráfico, sino que se alijaba y pasaba directamente a los navíos de mercaderes extranjeros» (Lohmann, 1949), que abundaban en las inmediaciones de las Azores, o se transfería directamente desde América — vía Brasil, Azores, Madeira y Lisboa- a través del sistema de tráfico fraudulento organizado por los portugueses y tolerado por la Corona (Vilar, 1969). Es así como se equilibraba la balanza comercial, violando sistemáticamente la prohibición mercantilista de exportación de especies metálicas, incompatible con el desequilibrio en los intercambios.

\section{TRES SIGLOS DE PLATA Y AZOGUE}

El tesorero de la Corona había estimado en 1560 que en Nueva España el precio de venta del azogue determinaría la entrada en explotación de las minas de plata en razón de su riqueza; al precio de mercado — ganando la Corona cincuenta ducados por quintal - sólo podían beneficiarse minerales que contuviesen al menos tres onzas de plata por quintal de tierra (riqueza del 0,19 por 100); era recomendable, sin embargo, que la Corona ganara menos en la venta del azogue y bajase su precio, porque a 80 ducados el quintal de azogue podrían beneficiarse los minerales de dos onzas, y a 60 ducados los de una onza de plata por quintal de tierra $(0,063$ por 100). Como éstos eran los más abundantes, a 60 ducados el azogue podrían producirse 5.000 quintales $(230 \mathrm{Tm}$.) de plata al año, consumiéndose otros tantos de azogue (porque «cada día se pierde tanto azogue como se saca de plata»). Por eso, la política de bajos precios del azogue fue utilizada 


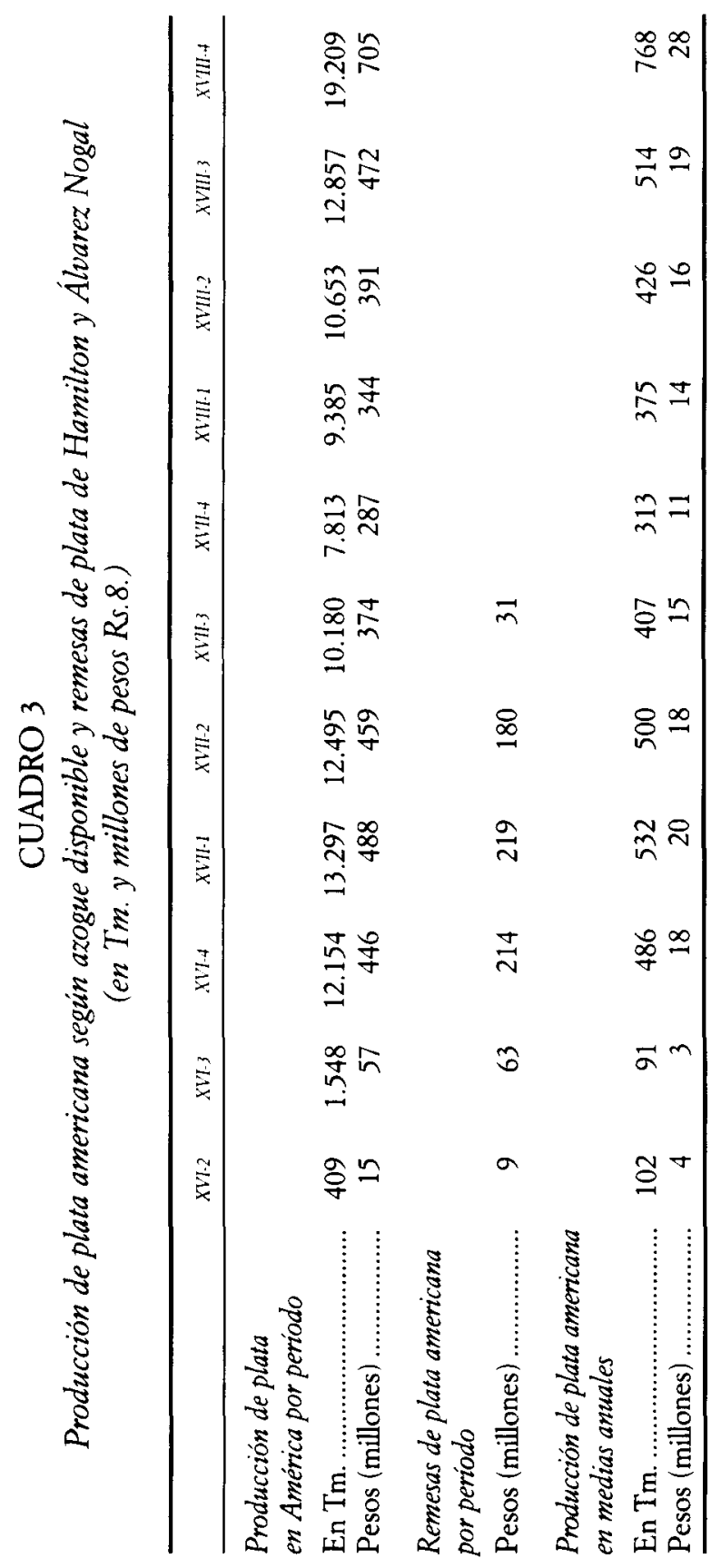


como instrumento de fomento, de control fiscal de la producción de plata y como censo de mineros, lo que tuvo que dificultar el contrabando en México, aunque el aumento del rendimiento del azogue y la plata de rescate (producida directamente por los peones, a modo de salario en especie, y no declarada en las cajas reales) encontró la forma de superar los controles. Los virreyes de Nueva España fijaban la cantidad de azogue distribuido en función de la plata registrada mediante una ratio, referida a los rendimientos medios declarados en cada demarcación, que se situaron desde el siglo XVII en torno a una libra de azogue por cada marco de plata (con una relación de $2: 1$ ). Como esta medida de fomento incentivaba el fraude -que aumentó fuertemente a partir de 1630 - en el siglo XVIII se combinó con una política de reducción de la fiscalidad: se cambió el quinto por el diezmo de la plata a partir de 1730 y se rebajó la del oro hasta el 3 por 100 a partir de 1777 , lo que incentivó el registro del metal extraído (Lang, 1977; Fisher, 2000).

La política de precios del azogue efectivamente practicada en Nueva España con carácter general por la Corona durante los tres siglos siguientes fue la recomendada por don Fernando de Portugal. El objetivo establecido en su carta se superó por primera vez en 1588 (en que se remitieron 6.120 quintales), y las remesas de Sevilla a Indias entre esa fecha y 1645 alcanzaron un promedio anual de 4.692 quintales. Del Gráfico 3 se deduce que el segundo cuarto del siglo XVII es el primero que registra una caída de los envíos de azogue a Sevilla, aunque el descenso de la producción de Almadén se suplió con importaciones desde Idria, para aumentar los envíos a América, y sobreexplotando la mina de Huencavélica, que alcanzó en 1643-1645 un máximo de producción de 9.000 quintales/año (de 12.000, contando el contrabando), pero en 1648 la veta de cinabrio de alta ley quedó cortada por una falla de roca caliza que redujo considerablemente la producción de la mina peruana hasta 1743 (Lohmann, 1949), y en 1786 se produjo el derrumbe que la dejó prácticamente inutilizada (Lang, 1986). Obsérvese en todo caso que la contracción del trasvase de azogue hacia América durante la segunda mitad del xvu fue muy inferior a la del tráfico global: si durante la primera mitad del siglo las $11.222 \mathrm{Tm}$. trasvasadas supusieron el 0,66 por 100 del movimiento naval, las 4.885 de la segunda mitad supusieron el 1,66 por 100 del mismo, que se redujo a 313.000 Tm., un 18,4 por 100 del registrado durante la primera mitad (García-Baquero, 1999), lo que se explica en parte por la expedición de 18 «navíos de azogues» y la suspensión de 28 flotas entre 1630 y 1710 (Lang, 1998). 
Para los gestores de la época éstos son años de «escasez de mineral» en Almadén, pero se trata de una escasez relativa, en relación con el precio por quintal pagado por la Corona a los Fúcar (29,33 ducados), que no varió desde el asiento de 1615-24, aunque ya en 1625-34 ése había sido el coste medio de producción, que se elevaría fuertemente a partir de 1636. El precio de adquisición por parte del monarca se encontraba determinado por el de venta a los mineros en las Indias, limitado a su vez por la demanda y el precio relativo de la plata en el mercado y por la política de fomento de la producción de plata, que exigía mantener bajos los precios del azogue. Pero la Corona disponía de ancho margen y en esta política aparentemente se excedió, hasta el punto de hacer económicamente inviable cualquier nueva inversión en Almadén en un período, como el de comienzos de los años cuarenta del siglo XVI, en que la monarquía soportaba la rebelión general que conduciría a su hundimiento definitivo y Olivares («tan testarudo que se quebraría antes de doblegarse») buscaba dinero por todas partes (Elliott, 1990). En realidad, la insuficiencia endémica de azogue durante todo el siglo XVII no se debió a causas técnicas o mineralógicas, sino a la creciente descomposición de las finanzas de la Corona, que impidieron mantener un flujo mínimo de inversión, e incluso el gasto corriente de funcionamiento de las minas (Lang, 1998).

Sólo en 1642, tras la quiebra de los Fúcar en vísperas de la caída de Olivares, se accedería a aumentar en un 30 por 100 el precio de adquisición, estableciéndolo en 37,33 ducados, con lo que los precios de Almadén quedaron prácticamente equiparados a los de Huencavélica, cuyo asiento de 1645 lo fijó en 35,6 ducados el quintal - una vez deducido el quinto real一, reduciendo en 83 reales el coste del asiento de 1630 - que ya había reducido en 32 reales el de asientos anteriores-(Lohmann, 1949). Ése es el momento en que la política industrial del azogue adoptó su forma definitiva, pasando Almadén a explotarse directamente por el Consejo de Castilla, con lo que la mina quedó integrada en el conjunto de instrumentos de la política monetaria.

Una vez resuelto aparentemente el problema agente/principal mediante la gestión pública directa, la tensión ejercida sobre la reducción de los costes de producción dio pie en Almadén a la introducción de los «hornos Bustamante», con los que se consiguió beneficiar minerales pobres, hasta entonces desechados. La historia de los hornos empleados en la mina sirve para sintetizar las principales etapas tecnológicas del beneficio del azogue, correlato, a su vez, de las vicisitudes del mercado de la plata: hasta el asiento de 1563-72 el metal se había cocido en hornos tradicionales lla- 
mados «de jabecas» de bajo rendimiento y alto consumo de combustible, que se usaron también en Huencavélica, incorporándoseles algunas mejoras en torno a 1590 y a partir de 1609. Los Fúcar introdujeron en Almadén ocho hornos de reverberación, de diseño alemán, que fueron renovados entre 1609 y 1629, mejorando el rendimiento en un tercio y denominándoseles a partir de entonces «hornos de buitrones», en los que el mineral se cocía en ollas de barro cerámico. Estos hornos se intentaron introducir en Huencavélica, pero no funcionaron (Lohmann, 1949).

En 1633 Lope de Saavedra Barba presentó un memorial para introducir en Huencavélica hornos de bóveda capaces de descomponer el cinabrio con el oxígeno del aire, recogiendo a continuación los vapores de mercurio en un condensador de aludeles. Tras la etapa de ensayo y experimentación, en 1640 ya había setenta hornos de este tipo funcionando en Huencavélica y en 1641 se reconoció al inventor como derecho de patente el 2 por 100 del valor de todo el azogue producido con sus hornos, pero la historia de la percepción por sus herederos resultó lastimosa. Un asentista de azogues del lugar - Juan Alonso de Bustamante- viajó a España y propuso en 1646 emplear aquí hornos de cámara algo perfeccionados. En 1648 se le nombró intendente de Almadén e implantó los hornos «de aludeles o de Bustamante», apropiándose el invento (Lohmann, 1949) en el mismo momento en que cambiaban las circunstancias del mercado de la plata y se llegaba a la asfixia financiera de la monarquía y al fin de su hegemonía política.

Pese a que el procedimiento fue reconocido en 1719 como el mejor por la Academia de Ciencias de París, entre 1725 y 1737 (precisamente durante la etapa en que el índice de precios se encontraba en su mínimo secular y la plata en el de máximo valor real) se recibieron múltiples propuestas arbitristas - experimentadas, sin éxito- tratando de duplicar el rendimiento del azogue. Se volvió a recibir una nueva propuesta en 1750 y otra en 1780. Finalmente, en 1793 se propuso adoptar el sistema de hornos utilizado en Idria. Seis años más tarde, Humboldt se encargaría de hacer un dictamen experto -en su calidad de Consejero de Minassobre las posibilidades de introducir mejoras en el laboreo del azogue y en la práctica de la amalgama por todo el continente americano.

La tónica que dominó todas las políticas relacionadas con el azogue y la plata a lo largo de estos tres siglos fue la continuidad. La relación entre producción de azogue y extracción de plata, así como las recomendaciones sobre política de precios de cesión del azogue a los mineros del siglo XVI, no variaron durante los siglos XVII y XVIII. Durante el siglo XVII 
en Nueva España el quintal se les vendió normalmente a 60 ducados ( 82 pesos, 5 temines, 9 granos y 13/17 avos) (Matilla, 1987, II). Los intentos de elevar el precio a 107 pesos en 1637, a 100 en 1675 y a 110 en 1677 fracasaron, y el precio se mantuvo en 60 ducados hasta 1767 (Lang, 1977). Una real cédula de 24 de marzo de 1739 concedió a los mineros de Guatemala la gracia de pagar sólo 30 pesos durante diez años (o sea, 21,8 ducados) como medida de fomento para que se explotasen las minas de leyes más cortas (de menos de 2 onzas por quintal, con riqueza del 0,13 por 100). Medidas de este tipo (con precios entre 30 y 45 ducados) se aplicaron con carácter selectivo (segmentando el mercado) al menos hasta 1776. En general, el precio a partir de 1760 volvió a ser de 60 ducados, pero fue bajando hasta 30 ducados (o 41,4 pesos Rs.8) en 1780, arrojando un promedio de 45,5 ducados o 62,7 pesos entre 1762 y 1781 (Humboldt, 1991), con resultados óptimos para el fomento de la actividad. En Perú el precio fue de 97 pesos hasta 1787, fecha en que se redujo a 71 (Castillo y Lang, 1995).

Y es que tras la caída de la demanda china y el derrumbe de la hegemonía imperial - junto al bache demográfico del tercer cuarto del siglo xvi en Castilla y en el resto de Europa - la única etapa de inflexión en las cifras de disponibilidades de azogue en el Nuevo Mundo fue el último cuarto del siglo xvII. La cifra de la primera mitad del siglo xvin ya volvió a ser similar a la de un siglo antes - aunque la irregularidad de los envíos fue el doble que la de entonces--, para duplicarse prácticamente durante la segunda mitad del mismo, con un último cuarto en que las remesas anuales alcanzaron casi la misma regularidad que a comienzos del siglo XviI (Cuadros 1 y 2; Gráfico 3). El estímulo para la dinamización de todo el mercado metálico provenía ahora tanto de Oriente como de Occidente: la triplicación de la población china volvió a ofrecer buenas oportunidades de arbitraje, al aumentar el precio de la plata un 50 por 100 respecto a la relación bimetálica europea durante la primera mitad del siglo (Flynn y Giráldez, 2000), las minas japonesas se habían agotado en el siglo anterior, y hasta el propio Japón experimentó escasez de numerario desde comienzos del siglo XVIII (Miyamoto y Shikano, 1998); además, la caída general de precios-plata de los bienes de consumo desde 1650 a 1726 (caída que en España fue del 1 por 100 anual) revalorizó la plata en relación a los otros productos. Hasta el último cuarto del siglo xvW no se recuperaría el nivel de precios-plata registrado a mediados del siglo xvII (Gráfico 4). Además, en 1668 Japón había prohibido la exportación de plata (y en 1696, la de oro), de modo que la CHIO tuvo que sustituir la saca de 


\section{GRÁFICO 4}

Corona de Castilla: precios. Producción de plata y precios de plata y vellón *

(Base: $1725-1750=100$ )

- PRECIOS-VELLÓN

-- PRECIOS-PLATA

- PRODUCCIÓN PLATA

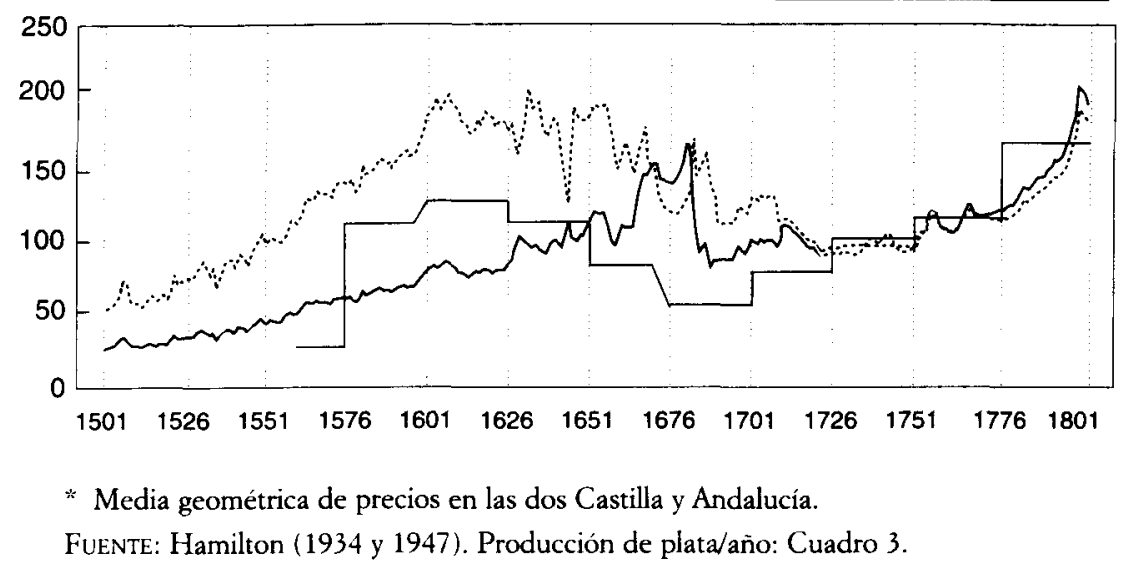

metales preciosos japoneses por importaciones desde la metrópoli, que se multiplicaron por tres entre 1660 y 1700 , fecha en que sólo el comercio de la CHIO con Bengala absorbía 6,1 Tm. de plata al año (Prakash, 1998).

En el último tercio del siglo XviI la rarefacción del dinero de plata era algo general en toda Eurasia: en España quedó patente por el exceso de demanda de vales reales entre 1780 y 1793 (Espina, 2000). En Nápoles se generalizó la utilización de los billetes de los bancos públicos. En seguida, la Revolución francesa y la nueva etapa de guerras acentuó hasta tal punto la demanda de dinero metálico que las autoridades acabaron por destruir otra vez la moneda fiduciaria, desencadenando la inflación de vales o apoderándose de las reservas metálicas de los bancos (Rosa, 2000). Además, la inseguridad bélica debió de aumentar la demanda de plata como moneda refugio, de modo que no es extraño que la producción de este metal -reflejo de la de azogue- experimentase una evolución paralela a la que se infiere de los cuadros 1 y 2 y del Gráfico 3, con la peculiaridad de que en los momentos de máxima producción los rendimientos decrecientes de la amalgama achataron las crestas de las curvas, como se observa en el cuadro 3 y en el Gráfico 2. Es a partir de 1765 cuando se disparó 
la producción de Almadén y se decidió finalmente modernizar la mina de azogue de Huencavélica, operación que acabaría con el estrepitoso fracaso de 1786.

La expansión de la segunda mitad del siglo xvil, sin embargo, no fue impulsada por el arbitraje bimetálico intercontinental, ya que el cambio oro/plata fue en China de 1:15, frente al europeo, situado en 1:14,5. En este caso, el comercio con extremo Oriente se vio favorecido por el precio y el coste relativo de la plata y los productos que le servían de contrapartida: el té, la porcelana y la seda, cuya demanda creció con la expansión europea. Aparentemente, pues, la recuperación de la credibilidad del bronce como metal monetizable (con mayor velocidad de circulación que la plata) permitió que la demanda china de plata monetaria sólo aumentase desde $115 \mathrm{Tm}$. al año a mediados del siglo xvI -en un contexto de recesión económica y demográfica- a $130 \mathrm{Tm}$. un siglo después, en etapa de plena expansión. Además, la función de demanda de plata se invirtió y adoptó pendiente positiva, porque su uso pasó a ser selectivo, empleándose sólo en las transacciones comerciales al por mayor (Glahn, 1998), y no como valor refugio, para protegerse contra la amenaza de degradación monetaria.

En un contexto como el de la segunda mitad del siglo xvII, el crecimiento continuado y casi explosivo de la producción de Almadén dio pie a una fuerte dinámica de exploración minera por todo el país y en América -aunque aquí sin resultados rentables (Lang, 1977)-, lo que llevó al descubrimiento y apertura de nuevos pozos - en el propio Almadén, a partir de 1744-46-, a la puesta en plena explotación de la mina de Almadenejos en 1759 o a la reapertura de antiguos pozos cerrados - como sucedió en 1778- Exigió también mejorar las técnicas de laboreo, con la introducción de nueva tecnología alemana a partir de 1752 - generalizada a partir del incendio de 1755- y la mecanización de las técnicas de desagüe a partir de 1765, que condujeron a estudiar la implantación de la primera «bomba de fuego» (la máquina de vapor de Wilkinson) desde 1779, encargada efectivamente a Inglaterra en 1786, aunque en 1799 todavía no se encontrase en funcionamiento. Esto es, la gestión directa de la política del azogue - que ya estaba permitiendo resolver razonablemente el problema de infrainversión, inherente al sistema de asientosconstituyó un obstáculo para gestionar la innovación, como postula la teoría de los fallos institucionales (Stiglitz, 1986).

La mejor ilustración de la fuerte demanda de plata a finales del siglo XVIII es la evidencia acerca de la necesidad de importar azogue para situarlo en América. La historia efectiva de la importación tras la introducción 
de la amalgama se había limitado hasta entonces, según Matilla (1987, I), a 2.000 quintales al comienzo de la declaración del estanco del azogue en 1559 - mientras Almadén se recuperaba del incendio- y a los tres asientos suscritos entre 1614 y 1646 con Albertinelli, Oberolz y Balbi para importar azogue de Idria. Estas importaciones permitieron remitir a Indias entre 1581 y 1645 envíos que superaron a la producción de Almadén en 70.391 quintales (3.238 Tm.: Cuadros 1 y 2 ).

Ante la decadencia irreversible de la mina de Huencavélica y la imposibilidad de forzar adicionalmente el crecimiento de la de Almadén —que ya soportaba el mayor peso del suministro- a partir de 1784, la disponibilidad de azogue se reforzó otra vez con importaciones desde Alemania. Antes, la rocambolesca aventura de la importación de azogue chino había permitido descubrir que ya había un precio único mundial en ese mercado y que el negocio no merecía la pena (Matilla, 1987, II). La vía alemana ya se había experimentado en 1764, vendiéndose el azogue en Nueva España a 63 pesos o 45,7 ducados el quintal. En 1785 José de Gálvez, Ministro de Indias, firmó un contrato por seis años, prorrogable por otros seis, con el Conde Pablo Greppi, de Milán —quien, a su vez, tenía suscrito otro con la Cámara Áulica austríaca, propietaria de las minas de Idria-, para suministrar un mínimo de 36.000 y un máximo de 60.000 quintales durante el sexenio (de 8.000 a 12.000 quintales al año), a un precio, descargado en los almacenes de Trocadero de Cádiz, de 38,6 ducados el quintal, que se vendería en América a 60 pesos o 43,5 ducados. De los 12.000 quintales suministrados en 1787, 4.000 (junto con 3.000 de Almadén) se remitieron a Buenos Aires - para suplir el cierre de Huencavélica- y los otros 8.000 (junto a los 10.000 restantes de la producción de Almadén) a Nueva España.

El contrato con Greppi no se prorrogó, sino que en 1791 se firmó una convención entre las cortes española y austríaca por la que ésta suministraría directamente a la primera 6.000 quintales de azogue al año (ampliables en otros 4.000). La vigencia inicial de aquella convención fue de seis años, prorrogables por otros seis, y el precio convenido el mismo del contrato de Greppi (con un descuento del 3 por 100 por pronto pago), pero entregando el mineral en Trieste, que en 1797 fue conquistada por Napoleón, aunque un año después los austríacos habían restablecido la producción y suministraban 10.000 quintales al año. Pero el problema no se encontraba ya en el suministro del mineral, sino en su reexportación a América, dado el bloqueo naval decretado por Inglaterra desde 1796, que no pudo romperse hasta 1800 , cuando Almadén producía ya 20.000 
quintales de mercurio al año (Humboldt, 1991). Desde 1797, sin embargo, la metrópolis había tenido que suspender sus pretensiones de monopolio del comercio con América, que las colonias contemplaban ya como yugo insoportable.

\section{CONCLUSIÓN}

La ventaja comparativa proporcionada por los metales americanos, el azogue de Almadén y las oportunidades de arbitraje en el comercio oro/plata con China hicieron económicamente inexpugnable al imperio español hasta que la relación del valor de la plata respecto al del oro quedó igualada en ambos continentes en torno a 1640, registrándose con ello un primer episodio de equiparación de precios a escala global. La fecha marca el final de la dinastía Ming -cuyo colapso fue provocado por el derrumbe de las importaciones de plata (Glahn, 1998) - y la derrota de los Austrias.

A partir del momento en que cesaron los beneficios extraordinarios de que había disfrutado hasta entonces la monarquía de España —en su calidad de productor mundial de plata por excelencia - el determinante del mercado monetario internacional habría de ser la relación entre el coste de producción del metal, los precios de los restantes productos y los costes comerciales y de transacción. El coste de sostenimiento del imperio se había venido financiando en gran medida creando activos financieros respaldados por las rentas de monopolio y los beneficios del arbitraje intercontinental (Espina, 2001b). Desaparecido éste, los factores de ventaja tenían que basarse en la competencia financiera y en la habilidad y lo acertado de las estrategias comerciales. Pero la monarquía -incapaz de mantenerse imparcial en la imprescindible función de regulación del sistema de crédito- había destruido con su voracidad las bases del poder financiero castellano y había fiado la victoria comercial a la coerción y el monopolio colonial, más que a la creación de factores de competitividad real basados en la inversión a largo plazo, incompatible con la ausencia de derechos individuales y con la política depredatoria (Olson, 2000) practicada por la monarquía (Espina, 2001b). De este modo, si al final del siglo xvi la renta per capita española había conseguido converger con la media de la de Europa Occidental, en 1700 era sólo un 88 por 100 (algo menos que en 1500) y en 1820 un 86 por 100 de aquélla (Maddison, 2001).

Porque el monocultivo de aquella ingente ventaja comparativa permitió a la Corona descuidar la creación de verdaderas «ventajas competitivas», 
y su agotamiento explica la derrota y subsiguiente subordinación de la monarquía española respecto a su oponente francesa en el siglo XvIII (Espina, 2001a). Pero ni siquiera la alianza casi permanente de las dos ramas de la dinastía Borbón a lo largo del siglo XvW impediría que una y otra perdieran relevancia a largo plazo, pese a la ayuda que supuso la fuerte recuperación de la capacidad de producción de azogue y plata a partir de 1726 - al reaparecer la bomba absorbente, debido a la explosión demográfica china- y la impresionante expansión de la producción de plata registrada durante la segunda mitad del siglo, tras casi cien años de caída de precios-plata de los productos, que permitieron recuperar la rentabilidad de la producción de especies metálicas. La estrategia finalista de dominación territorial extensiva practicada por la dinastía Borbón tuvo menos éxito que la estrategia intensiva anglo-holandesa, en la que el «collar de perlas alrededor del globo» de sus imperios marítimos desempeñó un carácter meramente instrumental para el comercio y el desarrollo de la producción en la metrópoli (Landes, 1999). El resultado fue que entre 1500 y 1820 el crecimiento anual medio de la renta per capita en España y Francia $(0,13$ y 0,16 por 100$)$ fue aproximadamente la mitad que el de Holanda y del Reino Unido (0,28 y 0,27 por 100) (Maddison, 2001).

No bastó para remediar la decadencia española el intento final de apelar a la ciencia y la tecnología mineras, con las misiones encomendadas a Jussieu, Bowles, Jorge Juan, Ulloa, Delhuyar, Nordenflicht, o el propio Humboldt. La pretensión de los reformistas ilustrados tuvo sólo un éxito moderado precisamente porque el avance económico necesitaba de fuertes inversiones y éstas sólo podían ser protagonizadas por una clase capitalista autónoma, cuyo ascenso resultaba dificultado por la inseguridad jurídica y el intervencionismo propios del régimen absolutista que, en lugar de amplificar el funcionamiento del mercado, lo obstruían, impidiendo el crecimiento (Olson, 2000).

Cuando estas dificultades se obviaron, como sucedió con el gremio y el Tribunal de la minería de Nueva España, patrocinados por José Gálvez a partir de 1774 , surgieron iniciativas de inversión tan impresionantes como las de Veta Vizcaína, en Real del Monte, o la valenciana, en Guanajuato, fruto principalmente de la reinversión del capital comercial que floreció tras la adopción del libre comercio en 1778. Pero la iniciativa fue tardía y la diversificación productiva no tuvo tiempo de avanzar gran cosa, de modo que entre 1782 y 1796 el 56 por 100 del valor de las importaciones americanas hacia Barcelona y Cádiz siguió consistiendo en oro y plata (Fisher, 1998). 


\section{BIBLIOGRAFÍA}

Alonso Barba, Álvaro (1640): Arte de los metales, Madrid, Imprenta del Reyno (BNE: R.7731b).

Álvarez, C. (2000): «La estrategia de la Real Hacienda en la negociación del crédito de los Austrias», en BERNAL (ed.), pp. 439-456.

Álvarez Nogal, C. (1998): "Las remesas americanas en las fínanzas de la real Hacienda. La cuantificación del dinero de la corona (1621-1675)», Revista de Historia Económica, año XVI, núm. 2, pp. 453-488.

Bernal, A. M. (2000): «Remesas de Indias: de «dinero político» al servicio del imperio a indicador monetario», en BERNAL (2000), pp. 353-384.

Bernal, A. M. (ed.) (2000): Dinero, moneda y crédito en la Monarquia Hispánica, Madrid, Marcial Pons.

Carande, Ramón (1987): Carlos $V$ y sus Banqueros, Tomo 1: La vida económica en Castilla (1516-1556), t. 2: La bacienda real de Castilla, 3. a ed., Crítica, Junta de Castilla y León.

Castillo, M., y LANG, M. F. (1995): Metales preciosos: unión de dos mundos, Muñoz Moya y Montraveta, editores.

Cinaudhury, S. (1998): «The Inflow of Silver to Bengal in the Global Perspective, 1650-1757», FlynN et alia (Sess. Orgs.), pp. 85-96.

Cipolla, C. M. (1999): La Odisea de la Plata Española, Critica (1. a ed.: Conquistadores, Pirati, Mercatanti, Bolonia, Il Mulino, 1986).

ElliotT, J. H. (1990): El Conde-Duque de Olivares, Crítica (1. a ed. en inglés de 1886).

ESPINA, Á. (2000): «De la caída del Antiguo Régimen a la II República: un enfoque neokeynesiano de la economía española», Sistema, núms. 155-156, abril, pp. 175-209.

- (2001a): «La resistencia a la Monarquía de España y el sistema europeo de estados», Sistema, núm. 164, septiembre.

- (2001b): «Deuda pública y confianza en el gobierno de España bajo los Austrias», Hacienda Pública Española, núm. 156, 1/2001.

FISHER, J. R. (2000): «Mining and imperial trade in 18th-Century Spanish America», en FLYNN et alia (Sess. Orgs.), pp. 109-119.

FlynN, D. O., y GiRÁldez, A. (1996): «China and The Spanish Empire», Revista de Historia Económica, año XIV, núm. 2, primavera-verano, pp. 309-338.

- (1998): «The Philippines as imperial profit center in the 16th and 17Th centuries», en FLYNN et alia (Sess. Orgs.), pp. 61-71.

- (2000): «Imperial monetary policy in global perspective», en BERNAL (2000), pp. 385-404.

Flynn, D. O.; Morineau, M., and Von Glahn, R. (Sess. Orgs.) (1998), Monetary bistory in global perspective, 1500-1808, NúNez (ed.), vol. B 6.

GarCía FuENTES, L. (1999), «El tráfico trasatlántico», Historia de España Menéndez Pidal, vol. XXVII, La formación de las sociedades iberoamericanas, 1578-1700, pp. 151-178.

GarCía-BAQUero GonzÁlez, A. (1996): «Las remesas de metales preciosos americanos en el siglo xviI: una aritmética controvertida», Hispania, núm. 56, pp. 203-266. 
González, M. J., y Del Hoyo, J. (1983): «Dinero y precios en la España del siglo xvi. Una confirmación de la tesis de Hamilton», Moneda y Crédito, núm. 166, septiembre, pp. 15.46.

Hamilton, Earl J. (I: 1934): El Tesoro americano y la revolución de los precios en España. 1501-1650 (edición citada, Barcelona, Ariel, 1975).

HumboldT, Alejandro de (1991): Ensayo político sobre el reino de Nueva España, México, Porrúa (1. ${ }^{2}$ edición en español, Paris, 1822).

Landes, David S. (1999): La riqueza y la pobreza de las naciones. Por qué algunas son tan ricas y otras son tan pobres, Barcelona, Crítica ( $2 \mathrm{~W} . \mathrm{W}$. Norton \& Co. Inc., N. York, 1998).

LANG, M. F. (1977): El monopolio estatal del mercurio en el México colonial (1570-1710), México, F. C. E.

- (1986): «El derrumbe de Huencavélica en 1786. Fracaso de una reforma borbónica», Histórica, vol. X, núm. 2, Lima, pp. 213-226.

- (1998): Las Flotas de La Nueva España (1630-1710). Despacho, Azogue, Comercio, Sevilla, Muñoz Moya.

Lohmann Villena, Guillermo (1949): Las minas de Huencavélica en los siglos XVI y XirI, Sevilla, Escuela de Estudios Hispano-Americanos.

Maddison, Angus (2001): The World Economy. A Millennial Perspective, OCDE, Development Centre Studies.

Matilla Tascón, Antonio (I y II): Historia de las Minas de Almadén, vol. I: Desde la época romana basta el año 1645 (Gráficas Osca, 1958), y vol. II: Desde 1646 a 1799, Madrid, Instituto de Estudios Fiscales, 1987.

Miyamoto, M., y Shikano, Y. (1998): «The Emergence of the Tokugawa Monetary System in East Asian International Perspective», en FLYNN et alia (Sess. Orgs.), pp. 133-153.

MONTESQUiEU (1734): Considérations sur les causes de la grandeur des Romains et de leur décadence, Oeuvres, Roger CAllcors (ed.), 2 vols., Gallimard (Bibliothèque de la Pléiade).

Morineau, M. (2000): «En medio del vado: Gold is beautiful», en BERNAL (2000, pp. 182-202).

Munro, J. H. (1999a): «The Low Countries' Export Trade in Textiles with the Mediterranean Basin, 1200-1600», University of Toronto, Department of Economics Working Papers, 99-01: bitp://www.chass.utoronto.calecipa/archive/UT-ECIPA-MUNRO-99-O1.pdf

- (1999b): «The Monetary Origins of the "Price Revolution" Before the Influx of Spanish-American Treasure: 1470-1540», University of Toronto, Department of Economics Working Papers, pp. 99-02 [una primera versión en FLYNN et alia (Sess. Orgs.), pp. 35-50].

NEF, John (1941): «Silver Production in Central Europe, 1450-1618», Joumal of Political Economy, núm. 49, pp. 575-591.

Núnez, C. E. (ed.) (1998): Proceedings. Twelfth International Economic History Congress, Madrid, August, 1998, Sevilla, Fundación Fomento de la Historia Económica, varios vols.

Olson, Mancur (2000): Power and Prosperity, N. York, Basic Books.

PRAKASH, Om. (1998): «Precious metal Flows into India in the Early Modern Period», en FLYNN et alia (Sess. Orgs.), pp. 73-84. 
Reher, D., y Ballesteros, E. (1993), «Precios y salarios en Castilla: La construcción de un indice de salarios reales, 1501-1991», Revista de Historia Económica, vol. IX, núm. 1, pp. 101-151.

ROSA, Luigi de (2000): «De la moneda de metal al papel moneda (cartas de crédito) en el reino de Nápoles: el papel de los bancos públicos», en BERNAL (ed.), pp. 658-677.

Ruiz Martin, Felipe (1990): Pequeño Capitalismo, Gran Capitalismo, Barcelona, Crítica (primera edición francesa de 1965).

Stiglitz, J. (1986): La economía del sector público, versión española de A. Bosch, editor, 1. ${ }^{\mathrm{a}}$ ed., 1988.

TePaske, J. J. (1998): «New World Gold Production in Hemispheric and global Perspective, 1492-1810», FLYNN et alia (Sess. Orgs.), pp. 21-34.

VIIAR, P. (1969): Oro y Moneda en la Historia. 1450-1920, Barcelona, Ariel.

VON Glahn, R. (1998): «Money-use in China and Changing Patterns of Global Trade in Monetary Metals, 1500-1800», en FLYNN et alia (Sess. Orgs.), pp. 51-60. 